\title{
The effect of sulfate contents on the surface properties of iron-manganese doped sulfated zirconia catalysts
}

\begin{abstract}
The ironï manganese doped sulfated zirconia catalysts were prepared via precipitation method; the sulfation was carried out by impregnation with different amounts of sulfate $(4 \%$, $10 \%$ and $16 \%$ SO4i 2 by weight) with the addition of Feï Mn doped and calcined at $600{ }^{\circ} \mathrm{C}$ for $3 \mathrm{~h}$. The prepared catalysts were characterized by TGA-DTA, XRD, BET, FT-IR, TEM, TPD-NH3 and XPS. XRD and BET results revealed that the addition of sulfate imparts special stabilization to the catalytically active tetragonal phase of zirconia. All the ironi manganese doped sulfated zirconia catalysts were found to have strong acid sites, high surface area and small crystallite size.
\end{abstract}

Keyword: Ironï manganese doped sulfated zirconia 4\% SO4ī 2 by weight (FMSZ-4); Sulfation; Dopants; Crystallite size 